\title{
PRESENÇA DE ÍONS NITRATO EM AMOSTRAS DE ÁGUA DE 26 REGIÕES DO RIO GRANDE DO SUL
}

\section{ARTIGO ORIGINAL}

FIORI, Raquel ${ }^{1}$, MARQUES, Tiago Queiroz ${ }^{2}$, AYRES, Cleiton Jaques $^{3}$, BOHN, $^{2}$ Barbara $^{4}$, BACK, Bruna 5

FIORI, Raquel. Et al. Presença de íons nitrato em amostras de água de 26 regiões do Rio Grande do Sul. Revista Científica Multidisciplinar Núcleo do Conhecimento. Ano. 06, Ed. 10, Vol. 02, pp. 79-98. Outubro 2021. ISSN: 2448-0959, Link de acesso: https://www.nucleodoconhecimento.com.br/quimica/ions-nitrato, DOI: 10.32749/nucleodoconhecimento.com.br/quimica/ions-nitrato

\section{RESUMO}

O sistema de abastecimento de água para fins de consumo humano é constituído de instalações e equipamentos que fornecem água potável para uma comunidade e deve estar de acordo com o que estabelece o dispositivo legal em vigor no Brasil, a Portaria de Consolidação no 5, de 28 de setembro de 2017 do Ministério da Saúde. Dentre os problemas de qualidade da água, ressalta-se a contaminação dos mananciais por nutrientes influenciando negativamente a diversidade biológica das águas. Um destes nutrientes é o nitrogênio em sua forma de ânion nitrato. Tendo em vista este cenário, o presente estudo tem como objetivo avaliar a presença de íon nitrato na água subterrânea, em especial nas 26 regiões do $R S$ do qual foi conduzido um estudo transversal sobre o solo. A metodologia adotada foi a cromatografia iônica feita com 249 amostras de água tratada no ano de 2018 na Seção Contaminantes do LACEN /CEVS/RS. Traçou-se características relevantes

\footnotetext{
${ }^{1}$ Doutoranda em Ensino de Química, Mestrado em Ciências e Tecnologia de Alimentos, pós-graduação em Ciências e Tecnologia de Alimentos, graduação em Química bacharelado, tecnológico e licenciatura em ciências e em Química. ORCID: https://orcid.org/0000-0003-4597-1559

${ }^{2}$ Graduação em Biomedicina. ORCID: https://orcid.org/0000-0002-7623-0916

${ }^{3}$ Graduação em Química. ORCID: https://orcid.org/0000-0003-0109-2317

${ }^{4}$ Graduação em Biomedicina. ORCID: https://orcid.org/0000-0002-3169-379X

${ }^{5}$ Graduação em Biomedicina. ORCID: https://orcid.org/0000-0003-1249-9374
} 
sobre os tipos de solo: latossolo, neossolo, nitossolo e chernossolo das regiões de coleta, sendo estes reconhecidos como de interesse no estudo. Como resultado, constatou-se que o íon nitrato foi mais incidente na Região da Serra, Norte e Noroeste Colonial. Tendo em vista as decorrentes atividades antropogênicas e a espacialização das fontes de poluição de origem agrícola revelando a contaminação dos corpos hídricos em função das características hidrogeológicas e hidroquímicos, evidenciou-se o fato da detecção deste íon nitrato nestas regiões e solos.

Palavras-chave: Água, ĺons, Nitrato, Solo.

\section{INTRODUÇÃO}

Os padrões de qualidade da água destinada ao abastecimento público são estabelecidos pela legislação de cada país. No Brasil, o padrão de potabilidade encontra-se descrito na Portaria de Consolidação n5, de 28 de setembro de 2017 do Ministério da Saúde (2017), que inclui limites quanto a presença de matéria orgânica em solução, desinfetantes, cianotoxinas, substâncias químicas, bem como a ausência de contaminação por agentes patogênicos.

Neste contexto, a Agência Nacional de Águas (ANA) avalia que o Brasil possui aproximadamente $12 \%$ da quantidade de água doce do mundo. A região Sul do Brasil detém em torno de $6,5 \%$ de água potável do país. Gerir este recurso natural como forma de regular e controlar o uso e proteção é fato diagnosticado em leis tais como: Código de Águas na forma do Decreto no 24643 de 10.07.1934, Lei das Águas sobre o n 9433 de 08.01.1997, Lei de criação da Agência Nacional de Águas $n^{\circ} 9984$ de 17.07.2000.

Apesar dos solos possuírem grande capacidade de absorção de contaminantes, funcionando como um filtro de grande eficácia, quando a capacidade de absorção é exacerbada, os aquíferos são contaminados. Mesmo que os microrganismos patogênicos sejam de maior preocupação, muitos contaminantes podem afetar as águas dos poços e atingir, consequentemente, aquíferos, principalmente em áreas rurais onde são aplicados agrotóxicos (SPIRO e STIGLIANI, 2008). 
Matson et al. (1998) menciona que a quantidade de fertilização nitrogenada utilizada na agricultura tem aumentado e as consequências agregadas a este fator são as perdas de nitrato do solo para os lençóis freáticos, sistemas marinhos e gases para atmosfera. Isto é, devido a lixiviação do nitrato, sua baixa energia está envolvida na adsorção do solo, assim como a alta solubilidade fazendo com que este íon seja carreado por percolação aos cursos d'água (DYNIA e CAMARGO, 1999). Assim, considera-se que regiões agrícolas sejam propensas a maiores concentrações desta substância, principalmente em locais que possuem solos de carga positiva, já que o nitrato, enquanto íon negativo interage com a fase sólida do terreno (APHA, 2000; RESENDE, 2002).

$\mathrm{Na}$ ingestão de água potável contaminada com nitrato, este se converte em nitrito no organismo humano, podendo surgir como produto de reações químicas entre o nitrito com as aminas secundárias ou terciárias e amidas provenientes dos alimentos. No pH entre 2,5 e 3,5 do estômago humano, podem ocorrer reações entre as nitrosaminas e nitrosamidas, surgindo tumores decorrentes delas. (BIGUELINI e GUMY, 2012).

Sabe-se ainda que o íon nitrato costuma ser encontrado em concentrações relativamente baixas em águas superficiais, enquanto em fontes de água subterrânea esses níveis podem ser ainda mais elevados. Além disso, é possível encontrá-lo em pequenas quantidades nas águas residuárias domésticas, bem como em concentrações superiores a $30 \mathrm{mg}$ de nitrato como nitrogênio por litro (N/L) nos efluentes de plantas de tratamento biológico nitrificante. Um limite de $10 \mathrm{mg}$ de nitrato como N/L em águas potáveis tem sido imposto em países como o Brasil e os Estados Unidos (SOUTO et al., 2006).

Seguindo os princípios do SUS (Sistema Único de Saúde), existe um Programa Nacional de Vigilância da Qualidade da Água para Consumo Humano (VIGIÁGUA) desempenhando um papel de importância na garantia e controle de qualidade da água destinada ao consumo humano no Brasil (MINISTÉRIO DA SAÚDE, 2019). No Rio Grande do Sul, o programa é coordenado pelo Centro Estadual de Vigilância em Saúde do Rio Grande do Sul (CEVS), pertencente à Secretaria Estadual de Saúde $\mathrm{RC}: 98539$

Disponível em: https://www.nucleodoconhecimento.com.br/quimica/ions-nitrato 
(SES), sendo as análises executadas pelo Laboratório Central do Estado (LACEN/RS).

No RS, no entanto, a falta de coleta e tratamento do esgoto sanitário é preocupante, pois o Estado coleta menos de $50 \%$ do esgoto gerado e trata cerca de $13 \%$ (PESSOA, 2017). Frente aos rigorosos padrões ambientais, estudos recentes vêm tentando desenvolver novas metodologias de tratamento biológico de efluentes, as quais possam otimizar as estratégias já existentes ou ainda implementar novos processos, fazendo o uso de microrganismos capazes de realizar a conversão do nitrogênio na forma amoniacal e nitrito em nitrogênio gasoso, sendo esta sua forma inerte (KIELING e SOARES, 2004).

Dentre os problemas de qualidade da água, ressalta-se a contaminação dos mananciais por nutrientes, e um deles pode se destacar como sendo o nitrogênio em sua forma de ânion nitrato.

Admitindo-se que o nitrato representa um risco à saúde pública, uma vez que é a principal forma de nitrogênio associada à contaminação, não somente de fontes superficiais, mas também subterrâneas, incluindo os aquíferos de zonas rurais e suburbanas que desempenham atividades agrícolas e agropecuárias, o presente estudo tem como objetivo avaliar a presença de íon nitrato na água subterrânea em especial nas 26 regiões do RS em 19 Coordenadorias Regionais de Saúde (CRS), as quais são responsáveis por 497 municípios. (RIO GRANDE DO SUL, 2017; CRQ$\mathrm{V}, 2008)$.

\section{MATERIAIS E MÉTODO}

\subsection{LOCAL DE PESQUISA E AMOSTRAGEM}

O LACEN/RS realiza análises consideradas de alta complexidade, apresentando-se como um grande contribuinte para a saúde. Atua no estabelecimento de indicadores e avalia a potabilidade da água e a qualidade dos alimentos em culturas de regiões envolvidas nos programas contratualizados. O objetivo principal é promover a 
segurança alimentar e prevenir agravos à saúde que possam ser causados por substâncias tóxicas.

As águas analisadas neste laboratório chegam ao Setor de Contaminantes envasadas em frascos âmbares com o conteúdo de 1 litro, juntamente com uma guia que indica o local de coleta (endereço, cidade, Coordenadoria Regional de Saúde responsável), a fonte (se superficial ou subterrânea), se residencial, pública ou coletada de linhas de tratamento da empresa responsável pelo abastecimento no município, e se a amostra é ou não tratada, bem como as condições climáticas na semana da coleta.

São realizadas pesquisas de resíduos de agrotóxicos em água para consumo humano, mais especificamente presença do agrotóxico glifosato e seu metabólito, ácido aminometilfosfônico (AMPA). Apesar de não ter sido detectado no decorrer das análises do ano de 2018 estes resíduos de agrotóxicos (FIORI et al., 2018), foi verificada nos cromatogramas analíticos uma grande incidência de picos de alguns ânions, tais como: brometo, cloreto, fluoreto, fosfato, nitrato e sulfato. Embora alguns sejam provenientes dos processos de tratamento e do próprio solo, outros não são esperados, como é o caso do nitrato, principalmente em muitas amostras.

As amostras de água foram coletadas de acordo com a classificação da Portaria de Consolidação nº 5, de 28 de setembro de 2017 do Ministério da Saúde:

- Solução Alternativa Individual de abastecimento de água para consumo humano (SAI);

- Sistema de Abastecimento de Água para consumo humano (SAA);

- Solução Alternativa Coletiva de abastecimento de água para consumo humano (SAC).

No período de Janeiro a Dezembro de 2018, foram coletadas 249 amostras de água em 26 regiões do Estado do Rio Grande do Sul: Alto Jacuí, Alto da Serra de Botucaraí, Campanha, Campos de Cima da Serra, Central, Centro-Sul, Fronteira Noroeste, Fronteira Oeste, Hortênsias, Jacuí Centro, Litoral, Médio Alto Uruguai, 
Metropolitano Delta do Jacuí, Missões, Nordeste, Noroeste Colonial, Norte, Paranhana, Encosta da Serra, Produção, Rio da Várzea, Serra, Sul, Vale do Caí, Vale do Rio dos Sinos, Vale do Rio Pardo e Vale do Taquari.

Os municípios integrantes deste monitoramento foram: Água Santa, Ajuricaba, Alegria, Ametista do Sul, André da Rocha, Anta Gorda, Aratiba, Arroio Bonito, Arroio Grande, Augusto Pestana, Áurea, Bagé, Barra do Rio Azul, Barra Funda, Barão do Triunfo, Barão do Cotegipe, Benjamin Constant do Sul, Boa Vista do Sul, Bossoroca, Bozano, Braga, Cachoeira do Sul, Camaquã, Campestre da Serra, Campina das Missões, Campinas do Sul, Candelária, Cândido Godói, Canguçu, Canoas, Carazinho, Carlos Barbosa, Caseiros, Catuípe, Caxias do Sul, Centenário, Cerro Branco, Ciríaco, Colinas, Coqueiro Baixo, Coqueiros do Sul, Coronel Barros, Coxilha, Crissiumal, Cruz Alta, Cruzaltense, Dilermando de Aguiar, Dois Irmãos das Missões, Dom Feliciano, Dom Pedrito, Doutor Maurício Cardoso, Doutor Ricardo, Encantado, Encruzilhada do Sul, Engenho Velho, Entre ljuís, Entre Rios do Sul, Erebango, Erechim, Erval Grande, Esmeralda, Estação, Estância Velha, Estrela, Fagundes Varela, Farroupilha, Faxinalzinho, Feliz, Floriano Peixoto, Forquetinha, Frederico Westphalen, Gaurama, Gentil, Getúlio Vargas, Gramado dos Loureiros, Guaporé, Herveiras, Horizontina, Humaitá, Ibiaçá, Ibirubá, ljuí, Ilópolis, Imigrante, Independência, Inhacorá, Ipê, Itapuca, Ivoti, Jacutinga, Jóia, Lagoa Vermelha, Mampituba, Maratá, Marau, Marcelino Ramos, Mariano Moro, Mato Queimado, Maximiliano de Almeida, Monte Alegre dos Campos, Monte Belo do Sul, Nonoai, Nova Bréscia, Nova Boa Vista, Nova Hartz, Nova Pádua, Nova Palma, Nova Petrópolis, Nova Prata, Nova Ramada, Nova Santa Rita, Novo Barreiro, Novo Cabrais, Novo Machado, Novo Tiradentes, Paim Filho, Palmitinho, Panambi, Paraí, Passo do Sobrado, Passo Fundo, Paulo Bento, Pedro Osório, Pejuçara, Pelotas, Pinhal da Serra, Planalto, Poço das Antas, Ponte Preta, Porto Alegre, Porto Mauá, Porto Vera Cruz, Porto Xavier, Protásio Alves, Quatro Irmãos, Quinze de Novembro, Redentora, Rolante, Rondinha, Saldanha Marinho, Sananduva, Santa Rosa, Santa Tereza, Santa Vitória do Palmar, Santo Cristo, Salvador das Missões, São Borja, São José das Missões, São José do Inhacorá, São Lourenço do Sul, São Marcos, São Paulo das Missões, São Pedro do Butiá, São Valentim, Sapucaia do Sul, 
Sarandi, Seberi, Severiano de Almeida, Sobradinho, Soledade, Taquaruçu do Sul, Tapejara, Tavares, Três Arroios, Três de Maio, Três Palmeiras, Três Passos, Trindade do Sul, Triunfo, Vacaria, Vale do Sol, Vale Real, Venâncio Aires, Vera Cruz, Viadutos, Vila Lângaro, Vista Alegre do Prata, Vista Gaúcha e Westfália pertencentes aos aquíferos Guarani, Botucatu, Jacuí, Serra Geral (Figura 1).

Figura 1. Mapa de localização das coletas de amostras

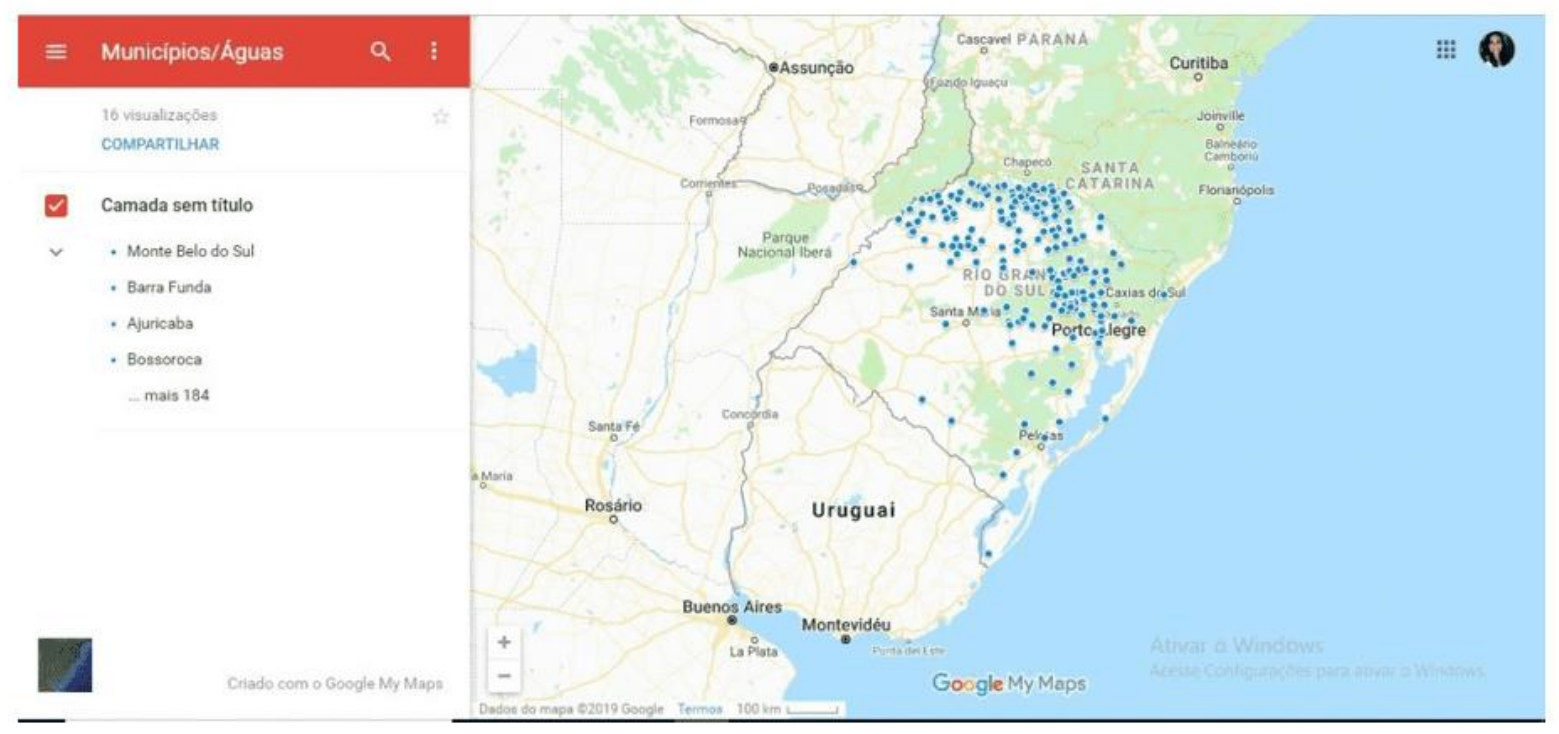

Fonte: elaborado pelos autores.

\subsection{PROCEDIMENTOS ANALÍTICOS}

Dentre as técnicas analíticas comumente empregadas na determinação de ânions, a cromatografia iônica destaca-se por apresentar inúmeras vantagens, como a possibilidade de analisar diversas espécies com a utilização de baixos volumes de amostra. Ela possui uma alta sensibilidade, além da facilidade e rapidez de separação, identificação e quantificação das espécies químicas, sejam elas compostos iônicos, orgânicos ou inorgânicos (AZEVEDO, 2019).

Esta técnica consiste em uma variante da cromatografia líquida que usa resinas de troca iônica para separar íons atômicos ou moleculares. A separação dos analitos é realizada isocraticamente ou por aplicação de gradiente com base em sua interação 
com a resina (AMARANTE et al., 2002). Os detectores utilizados por Cl são os eletroquímicos (condutividade e amperométrico) e espectométricos.

$\mathrm{Na}$ cromatografia iônica, ocorre uma interação eletrostática entre os íons presentes na amostra e os íons da fase estacionária que possui grupos com carga. Este processo de troca iônica verifica-se na condição de equilíbrio, e a eficiência da separação depende da interação existente e os grupamentos funcionais da fase estacionária (KLEIN, 2010).

Em amostras aquosas sem matriz orgânica é necessário apenas uma filtração por membrana com poros de diferentes tamanhos antes da injeção desta amostra. Somente para matrizes complexas considera-se um tratamento prévio para não ter interferência na sensibilidade e seletividade.

A análise foi realizada por cromatografia iônica e o cromatógrafo utilizado foi o 850 Professional IC, acoplado ao 858 Professional Sample Processador. A separação de substâncias foi realizada com a coluna Metrosep A Supp 7-250/4.0 e uma pré coluna RP Guard 2.5, adotando uma vazão de $0,7 \mathrm{~mL} /$ minuto, temperatura de $45^{\circ} \mathrm{C}$ e pressão de $15 \mathrm{MPa}$, com um loop de $200 \mu \mathrm{L}$ com o uso de detector de condutividade e tempo médio de análise de $31 \mathrm{~min}$ por amostra. Os dados gerados foram processados através do software MagIC Net 3.1.

Uma alíquota foi separada e transferida para um vial de $13 \mathrm{~mL}$ com uma seringa acoplada a um filtro de 0,45 $\mathrm{m}$. Foram preparados: Eluente $\mathrm{B}\left(1.0 \mathrm{mM} \mathrm{Na} 2 \mathrm{CO}_{3}+\right.$ $15.0 \mathrm{mM} \mathrm{NaOH}$ ); Eluente $\mathrm{C}\left(20 \mathrm{mM} \mathrm{Na}_{2} \mathrm{CO}_{3}\right.$ ); Supressores (Água Ultrapura e $5 \% \mathrm{H}$ ${ }_{2} \mathrm{SO} 4$ em solução aquosa); solução de lavagem com $13 \mathrm{~mL}$ metanol e $247 \mathrm{~mL}$ água ultrapura (POP/CON 60, Rev.03, 2019).

Esta otimização cromatográfica permitiu a detecção de diferentes ânions, sendo eles: brometo, cloreto, fluoreto, fosfato, nitrato, nitrito e sulfato através de uma solução padrão de multielementos a 10 ppm. A detecção de cada um só foi possível devido à existência de padrões pré-estabelecidos para cada um no equipamento (Figura 3). 
Figura 3. Cromatograma individual dos ânions provenientes da solução padrão dos multielementos

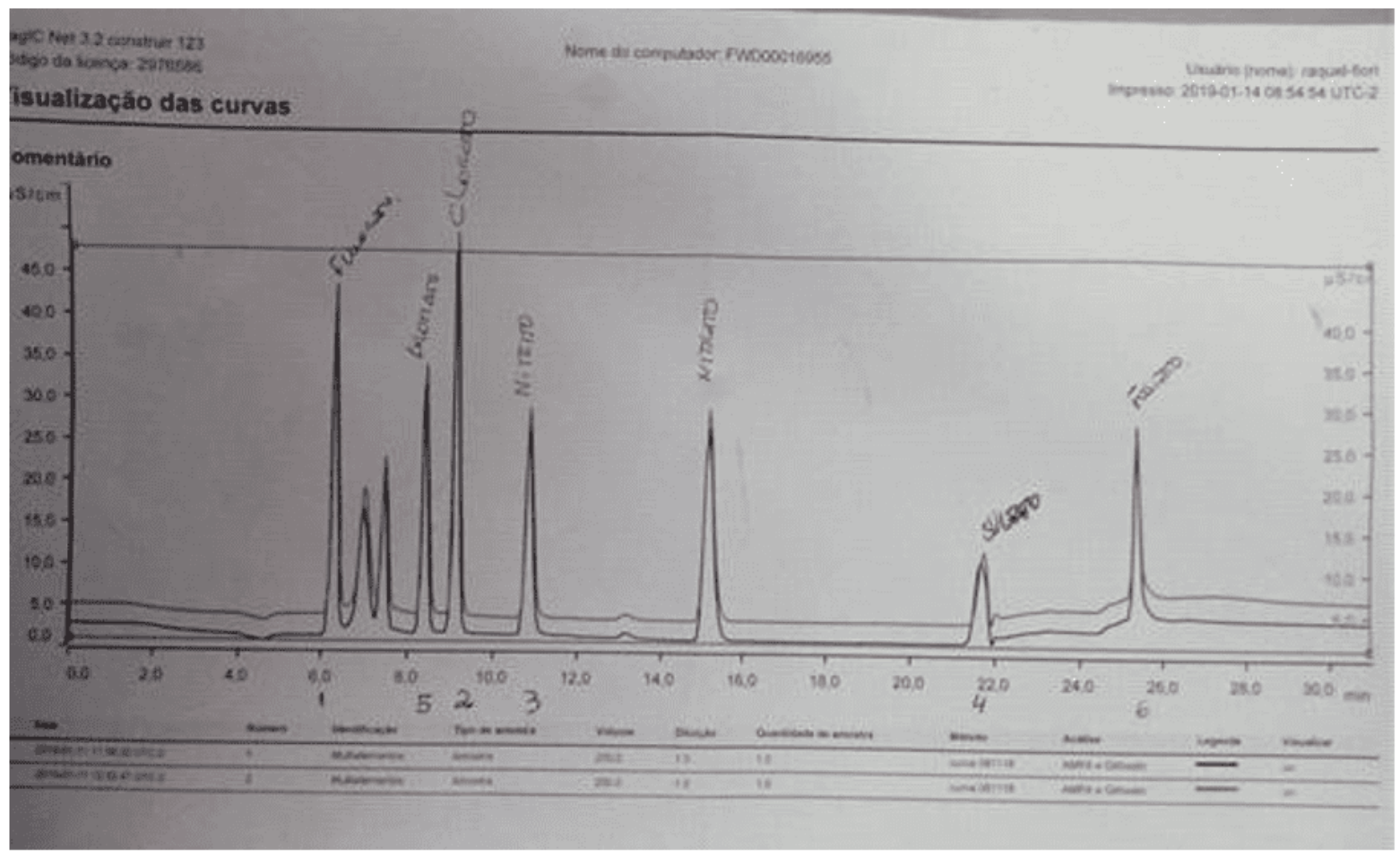

Fonte: Elaborado pelos autores.

No desenvolvimento de uma corrida cromatográfica de multielementos em uma única amostra, mais de um íon é detectado (Figura 3 e 4), a separação ocorre por troca iônica entre fase móvel (eluentes) e fase estacionária (coluna cromatográfica), devido a diferença de absortividade de cada analito e sua interação com o grupo trocador da coluna. (KLEIN, 2010). Os íons de menor carga como $\mathrm{F}^{-}, \mathrm{Cl}^{-}, \mathrm{NO}_{2}^{-} \mathrm{Br}^{-}$, $\mathrm{NO}_{3}{ }^{-}$têm menor tempo de retenção, eluindo primeiro enquanto os íons $\mathrm{PO}_{4}{ }^{-3} \mathrm{e} \mathrm{SO}_{4}{ }^{-2}$ eluem por último. A curva do cromatograma de multielementos está em azul claro na Figura 4.

Observa-se ainda que neste experimento não houve validação e nem quantificação, tendo em vista que o laboratório era direcionado para análise de resíduos de agrotóxicos. Mas, em função de que em todas as amostras detectava-se concomitante íons de ânions, resolveu-se fazer uma avaliação da problemática. 
Figura 4. Visualização das curvas de 9 amostras e o padrão de multielementos por cromatografia iônica

\begin{tabular}{|c|c|c|}
\hline 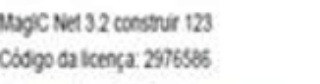 & Nome do coopuass. FW0000: & 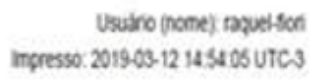 \\
\hline Visualização das curvas & & \\
\hline
\end{tabular}

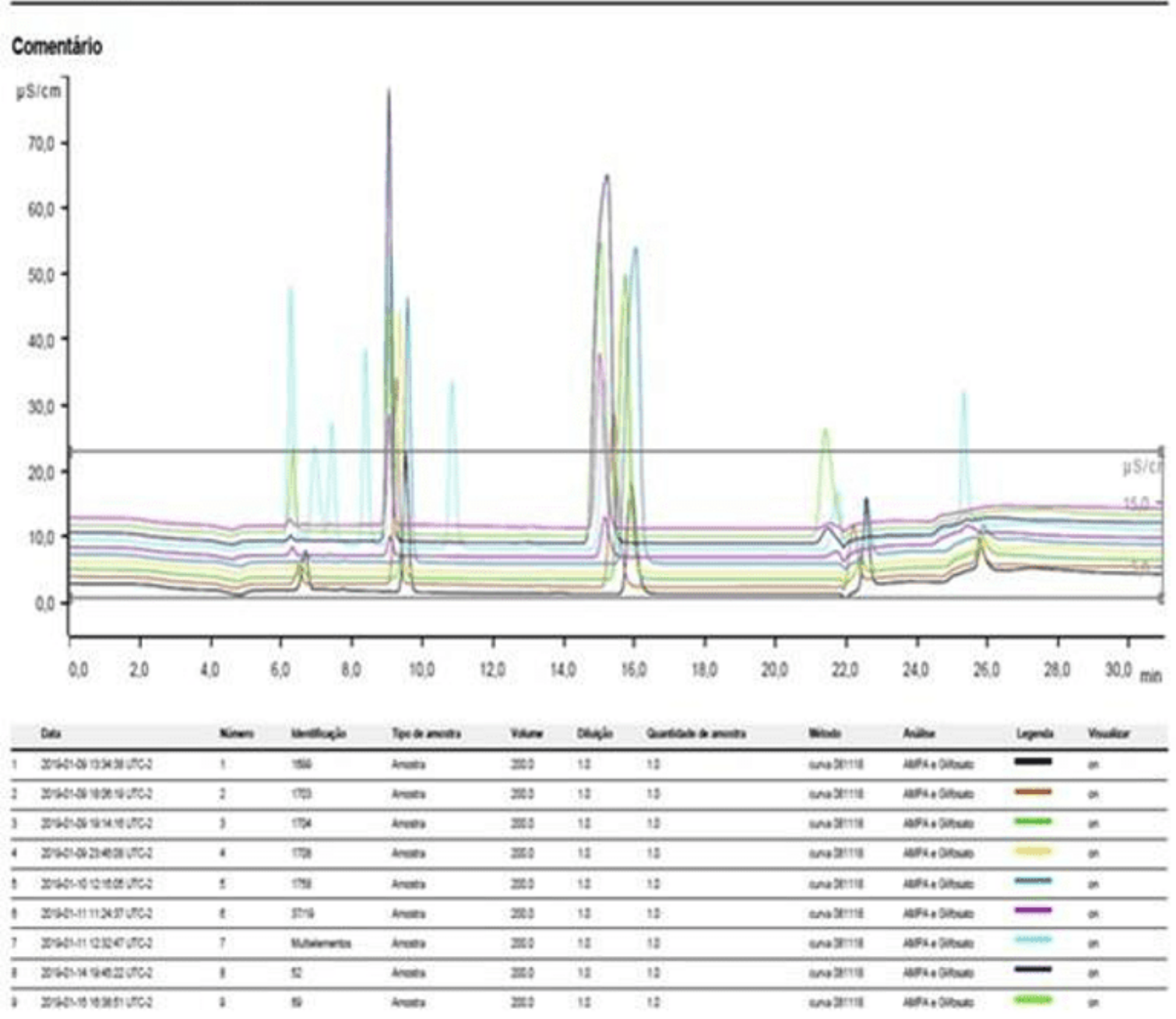

Fonte: elaborado pelos autores.

\section{RESULTADOS E DISCUSSÃO}

\subsection{PRESENÇA DO ÍON NITRATO}

Considerando o íon nitrato como o de maior interesse do estudo, foi avaliada a concomitância de outros íons. Desta forma, evidenciou-se que em 235 amostras

RC: 98539

Disponível em: https://www.nucleodoconhecimento.com.br/quimica/ions-nitrato 
com picos de íon nitrato, ocorriam, também, picos de íon cloreto, íon fluoreto e o íon sulfato. $\mathrm{O}$ íon nitrito, bromato e fosfato apresentaram baixa representatividade em 1 , 7 e 9 amostras, respectivamente.

$\mathrm{Na}$ análise cromatográfica, foram constatados picos que indicavam a presença dos seguintes íons: bromato em 7 amostras (2,8\%), cloreto em 248 amostras (99,6\%), fluoreto em 223 amostras (89,5\%), fosfato em 82 amostras (32,9\%), nitrato em 235 amostras $(94,3 \%)$, nitrito em 1 amostra $(0,4 \%)$ e sulfato em 215 amostras $(86,3 \%)$. Estes dados encontram-se representados no Gráfico

Gráfico 1 - Percentual de amostras com presença de íons

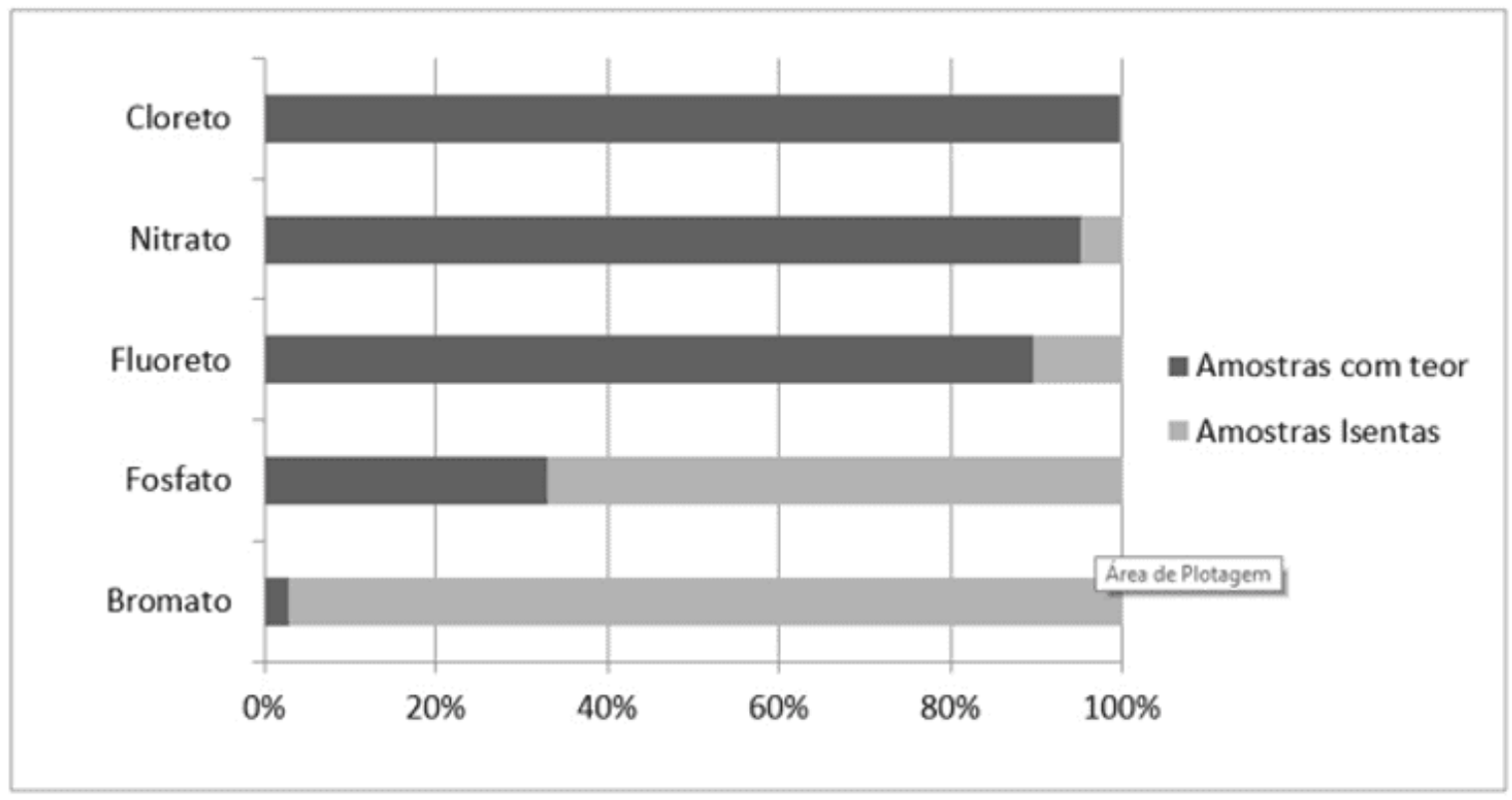

Fonte: Elaborado pelos autores.

Essa presença constante de íon nitrato gera preocupação, uma vez que pelo menos uma amostra de cada uma das 26 regiões abrangidas pelo Programa apresentou esse íon, sendo observadas maiores incidências nas seguintes: Região da Serra, onde 30 das 31 amostras tiveram o íon detectado, Região Norte com 27 das 28 amostras e Região Noroeste Colonial em todas as 25 amostras analisadas.

A legislação brasileira define obrigatória a fluoretação das águas desde 0 ano de 1974, de acordo com a Lei Federal 6.050 (BRASIL, 1974), como forma de prevenção

RC: 98539

Disponível em: https://www.nucleodoconhecimento.com.br/quimica/ions-nitrato 
de problemas dentários (cáries) e melhoria de saúde bucal. Atualmente é estabelecido o limite - Valor Máximo Permitido (VMP) de 1,5 mg de fluoreto/L de água (BRASIL, 2017). Tendo em vista que as análises realizadas no LACEN/RS são somente qualitativas, logo, apenas foi detectado a presença do íon fluoreto, mas não quantificado. Deste modo, admitiu-se a detecção do íon fluoreto como proveniente da fluoretação.

De acordo com a Portaria de Consolidação $n^{\circ} 5$, de 28 de setembro de 2017 do Ministério da Saúde (MINISTÉRIO DA SAÚDE, 2017), não consta índice permitido para o íon fosfato somente pela Resolução CONAMA n 357/05 para águas de classe II (VMP=0,025 mg. $\left.\mathrm{L}^{-1}\right)$. Na água, este íon pode estar sob formas iônicas em função do pH do meio.

Com relação ao íon bromato, este é formado em processos eletroquímicos no tratamento da água. Adicionalmente, o íon bromato é produzido quando dióxido de cloro é usado em água, quando o íon brometo está presente e quando a água é exposta a luz solar.

Sendo que a presença do íon nitrito ocorreu somente em uma amostra de água, que pode estar presente devido a decomposição de matéria orgânica nitrogenada, não se torna neste estudo alvo de diagnóstico como potencial agente poluidor. Quanto a presença do íon fosfato, depende da atividade de organismos, como fito plânctons e macrófitas que assimilam grande quantidade deste íon e outra parte precipita ao sedimento. Como a incidência foi de um número baixo de amostra, há a probabilidade de contaminação por eutrofização (BRASIL, 2006).

O íon cloreto é um dos principais íons inorgânicos encontrados na água. Em nosso estudo, ele foi detectado em 248 das 249 amostras. Utilizado para tratamento e purificação da água, o Ministério da Saúde (MINISTERIO DA SAUDE, 2017) estabelece como limite $250 \mathrm{mg}$ de cloreto/L de água. Da mesma forma que o fluoreto, não foi possível estabelecer a quantidade de cloreto presente em cada amostra, portanto, também foi admitida a detecção devido ao processo de tratamento. A presença de cloreto e fluoreto é comumente encontrada em águas que 
passam por tratamento para atingirem os níveis de potabilidade estabelecidos, e de acordo com a literatura, não apresentam riscos à saúde (KUHN ET AL., 2015).

O sulfato é um dos ânions mais abundantes na natureza. Em águas subterrâneas, normalmente está associado à dissolução de solos e rochas. Nas superficiais tem relação com o esgoto doméstico, efluentes de indústrias como as químicas, farmacêuticas, de celulose etc. Já em águas que recebem tratamento, o sulfato provém do uso de coagulantes, como os sulfatos ferroso, férrico e de alumínio. Tem seu limite na água de 250 mg. L L-1, segundo o Ministério da Saúde (2017), então sua detecção foi considerada natural ou advinda do tratamento.

Como caracterização da presença do íon nitrato e sua incidência, foi feito um traçado relevante sobre os tipos de solo: Chernossolo, Latossolo, Nitossolo e Neossolo (CRQ-V, 2008). Devido à sua elevada estabilidade e solubilidade, o nitrato tem uma baixa tendência para a precipitação e adsorção.

\subsection{SOLOS CARACTERÍSTICOS DA INCIDÊNCIA DE ÍON NITRATO}

Os latossolos são profundos, mineralizados e ácidos com faixas de pH entre 4,0 e 5,5. Possuem fertilidade reduzida devido a baixos teores de fósforo disponível, apresentando boa drenagem, mas precisam de correção química para utilização na agricultura, principalmente no verão. Trata-se de um solo maciço, levemente granulado e poroso, sendo essas características associadas ao fato de ser enriquecido com alumínio e óxido de ferro. Sua permeabilidade na água facilita o estabelecimento de níveis de umidade adequados às necessidades. Embora considerado um bom solo para o desenvolvimento da agricultura, os problemas de fertilidade apresentam-se como fatores limitantes, mas que podem ser corrigidos com níveis adequados de fertilizantes e corretivos.

A necessidade de aplicação de níveis elevados de fertilizantes nestes solos pode ser um fator associado à elevada presença de nitratos em suas águas. Os chernossolos são solos muito férteis e caracterizados pela presença da camada superficial densa e escura. Eles apresentam boa agregação de uma argila muito rica em matéria 
orgânica e nutrientes para as plantas, como cálcio, magnésio e potássio (RIO GRANDE DO SUL, 2017).

Os neossolos são solos pouco evoluídos, constituídos por material mineral ou por material orgânico com menos de $20 \mathrm{~cm}$ de espessura. Os nitossolos são normalmente profundos, bem drenados, estruturados, moderadamente ácidos e de fertilidade natural variável. Em função dos elevados conteúdos de argila, podem contrair e formar fendas predominantemente no sentido vertical no período de seca. (RIO GRANDE DO SUL, 2017).

Prevedello (1996) destaca que a capacidade de retenção de íons é particularmente acentuada nos solos argilosos e altamente intemperizados como os latossolos. Eles possuem uma mineralogia que desenvolve tanto cargas positivas como negativas, além de ter a capacidade de reter os principais ânions e cátions presentes em solução que possam vir a percolar no perfil do solo. Assim, é possível utilizar o potencial de retenção de água no solo como agente de estocagem natural e liberação lenta às nascentes e fontes dos cursos de água e lençóis subterrâneos.

Os pesquisadores Sangoi et al. (2003) compararam os valores numéricos obtidos na pesquisa nos dois solos nitossolo vermelho e neossolo quartzarênico, e verificou que a maior lixiviação de nitrato quando o fertilizante (uréia) foi incorporado ao solo foi no neossolo quartzarênico. Quantidades de nitrogênio lixiviada demonstram a grande capacidade que os solos argilosos, principalmente aqueles com alto teor de carbono, têm em disponibilizar nitrogênio para a solução do solo.

Os íons de nitrato interagem diretamente com a fase sólida por meio de reações de adsorção às cargas positivas dos colóides. Nos solos com mineralogia para as argilas com maior capacidade adsortivas (do tipo 2:1), mais comuns em regiões de clima temperado, a presença de cargas negativas cria uma resistência ao nitrato pela fase sólida, tornando a adsorção pouco provável, favorecendo a manutenção do íon em solução e facilitando a lixiviação (PRADO, 2013). 
De acordo com os autores Dynia e Camargo (1999) e Oliveira et al. (2000), os latossolos possuem características dinâmicas nos solos e rochas, sua mineralogia oxídica e seus ácidos podem estar favorecendo retenção de íons nitrato nas camadas superficiais. Tendo em vista a ausência de matéria orgânica, a fase sólida pode apresentar caráter eletropositivo sendo então possível que a adsorção do nitrato seja facilitada, pois não há confluência com os fosfatos que têm a preferência na ocupação das cargas positivas na camada superficial do solo.

Estudos envolvendo as propriedades elétricas dos solos são importantes para entender vários fenômenos ambientais, físicos e químicos relacionados à movimentação e à adsorção de íons no solo (CAMARGO e ALLEONI, 2006).

Donn e Menzies (2005) em seus estudos sobre lixiviação do íon nitrato em colunas de subsolos de latossolos profundos com presença de cargas variáveis ao longo do perfil avaliaram a influência da força iônica destes solos em comparação com outros ânions de acordo com a movimentação de nitrato. Os autores observaram, portanto, que houve um aumento na força iônica da solução e um aumento na densidade de cargas positivas e negativas de onde emergiram sítios de adsorção do nitrato. Ainda com o deslocamento pela água, a força iônica da solução diminuía e o íon nitrato era liberado para a solução novamente.

O nitrato tem uma baixa tendência para precipitação devido a estabilidade e solubilidade, então, tal é o grau de dificuldade para remoção da água. Para oferecer uma água adequada na distribuição entre a população, as empresas concessionárias misturam águas contaminadas com nitrato com outras de menor quantidade, assim ficando adequadas em termos de ingestão diária aceitável (MELO et al., 2011).

\subsection{MÉTODOS DE REMOÇÃO DO ÍON NITRATO}

Quanto a métodos disponíveis e utilizados para remoção de nitrato, pode-se citar a troca iônica, tecnologia de membranas e o tratamento biológico que se baseia no uso de microrganismos capazes de oxidar amônio a nitrogênio gasoso sob 
condições anóxicas. Assim, revelando-se como uma alternativa promissora à remoção de nitrogênio por processos de nitrificação e desnitrificação, oferecendo melhor eficiência com menores custos (KARVAT, 2017; KIELING; SOARES, 2004; REZENDE et al., 2016; TORRES, 2011).

Também podemos destacar a eletrodiálise que apresenta vantagens em comparação aos métodos tradicionais, uma vez que funciona de forma contínua, não requer adição de reagentes, não demanda mudanças de fase, além de minimizar a geração de resíduos poluentes ao meio ambiente (REZENDE, 2016).

\section{CONSIDERAÇÕES FINAIS}

Os recursos hídricos têm como destino inúmeras utilidades, sendo considerada como a mais nobre delas o abastecimento humano. Consequentemente, água empregada no abastecimento de comunidades, ainda que fora do perímetro urbano, deve possuir características toxicológicas e sanitárias adequadas, objetivando a prevenção de possíveis danos à saúde, bem como a garantia do bem-estar dos consumidores. (PINTO; ROMA; BALIEIRO, 2012).

Diante da dificuldade no desenvolvimento de métodos eficazes e viáveis economicamente para a remoção do nitrato em grandes quantidades de água como em mananciais superficiais e subterrâneos, é de interesse que haja mais estudos e implantação de controles sistemáticos nas diferenças sazonais e de concentrações, identificando os pontos críticos de contaminação, podendo estabelecer a prevenção e remediação assim como incentivar a prática da adubação verde e rotação de culturas incorporando ao solo massa verde que fixe o nitrogênio na planta impedindo a lixiviação (VIOLA, 2013).

Há poucos anos no Brasil, o assunto sobre gestão de águas não era relevante no âmbito de planejamento e nem prioritário na esfera científica, tendo em vista a grande quantidade de água distribuída pelo território nacional. Entretanto, por causas antrópicas, naturais ou induzidas, a redução da quantidade de água teve como consequência o desequilíbrio do ciclo hidrológico. 
Com base no estudo realizado, verifica-se que a contaminação do íon nitrato é significativa e silenciosa. Sugere-se, desse modo, monitorar os parâmetros de nutrientes nestas águas de abastecimento para viabilizar uma rediscussão destes poluentes com grau de periculosidade à saúde humana e ambiental. Enquanto não houver mitigação do problema no tratamento de esgoto com a contaminação dos lençóis freáticos, através do saneamento básico dos municípios, não poderá haver melhora na diminuição do íon nitrato no ecossistema aquático e nem diminuir os efeitos prejudiciais à saúde humana.

Portanto, fica a ressalva aos órgãos de fiscalização e ao Programa VIGIÁGUA que deem atenção a continuidade deste estudo como forma de quantificar este íon e validar este método por cromatografia iônica para monitorar as regiões expostas, assim como, sistematizar este monitoramento em seus Laboratórios Centrais de Saúde Pública.

\section{REFERÊNCIAS}

ANA. Agência Nacional de Águas (BR). Disponível em: https://bit.ly/3mMnUxF. Acesso em: 08/09/2021.

AMARANTE JUNIOR, Ozelito Possidônio et al. Glifosato: propriedades, toxicidade, usos e legislação. Química Nova. 25(4): 589-93, julho de 2002.

APHA. AMERICAN PUBLIC HEALTH ASSOCIATION. Qualidade da água potável e saúde pública (Documento de posição). Washington, Jan 2000.

AZEVEDO, Paola Cristiane de Costa. Determinação de ânions em amostras de resíduos da indústria do setor de óleo e gás por cromatografia iônica. (Trabalho de Conclusão de Curso). Florianópolis: Universidade Federal de Santa Catarina, Curso de Química, Departamento de Química; 2019.

BIGUELINI, Cristina Poll ; GUMY, Mariane Pavani. Saúde ambiental: índices de nitrato em águas subterrâneas de poços profundos na região sudoeste do Paraná. Revista Faz Ciência. 14(20): 153, 2012. 
BRASIL. Decreto no 24643, de 10 de julho de 1934. Dispõe sobre o Decreto do Código de Águas. Diário Oficial da União - Seção 1 - 20/7/1934, Página 14738 (Publicação Original).

BRASIL. Lei Federal no 6050, de 24 de maio de 1974. Dispõe sobre a obrigatoriedade da fluoretação das águas em sistemas de abastecimento. Diário Oficial da União. 27 jul 1974.

BRASIL. Lei Federal no 9433, de 08 de janeiro de 1997. Institui a Política Nacional de Recursos Hídricos, cria o Sistema Nacional de Gerenciamento de Recursos Hídricos, regulamenta o inciso XIX do art. 21 da Constituição Federal, e altera 0 art. $1^{\circ}$ da Lei $n^{\circ} 8.001$, de 13 de março de 1990, que modificou a Lei $n^{\circ} 7.990$, de 28 de dezembro de 1989. Diário Oficial da União - Seção 1 - 9/1/1997, Página 470 (Publicação Original).

BRASIL. Lei Federal no 9984, de 17 de julho de 2000. Dispõe sobre a criação da Agência Nacional de Águas - ANA, entidade federal de implementação da Política Nacional de Recursos Hídricos e de coordenação do Sistema Nacional de Gerenciamento de Recursos Hídricos, e dá outras providências. Diário Oficial da União - Seção 1 - 18/7/2000, Página 1 (Publicação Original).

BRASIL. Ministério da Saúde. Secretaria de Vigilância em Saúde. Vigilância e controle da qualidade da água para consumo humano. Ministério da Saúde, Secretaria de Vigilância em Saúde. - Brasília: Ministério da Saúde, 2006. 212 p. (Série B. Textos Básicos de Saúde).

BRASIL. Ministério do Meio Ambiente. Resolução CONAMA no 357, de 15 de junho de 2005.

CAMARGO, Otávio Antonio; ALLEONI, Luiz Reynaldo F. Reconhecimento e medida da compactação do solo. Artigo em Hipertexto. Disponível em: https://bit.ly/3oSWqZi. Acesso em: 21/07/2020. 
CONSELHO REGIONAL DE QUÍMICA 5 $5^{\text {a }}$ Região - CRQ-V. Câmara de agrotóxicos. I Mapeamento dos agrotóxicos utilizados no Rio Grande do Sul. Conselho Regional de Química da 5. Região. 1 Ed., Porto Alegre: 2008.

DONN, M.J.; MENZIES N.W. O efeito da variação da força iônica e da competição de ânions no desenvolvimento de acumulações de nitrato em subsoladores de carga variável. Australian Journal of Soil Research 43, 43-50.2005.

DYNIA, José Flavio; CAMARGO, Otávio Antonio. Retenção de nitrato num solo de carga variável, influenciada por adubação fosfatada e calagem. Pesq agropec bras. 34(1): 141-4, janeiro de 1999.

FIORI, Raquel et al. Validação de um método para análise de glifosato e AMPA em água de consumo humano usando cromatografia iônica. Revista Águas Subter. 32(3): 307-14,17 de setembro de 2018.

KARVAT, Manuelle. Utilização de resinas de troca iônica para remoção de nitrato em águas para abastecimento público. 2017 [citado 6 de dezembro de 2020]; Disponível em: https://bit.ly/3mMK6bq. Acesso em: 08/09/2021.

KIELING, Dirlei Dietrich. Estudo da remoção biológica de nitrogênio a partir de lodo nitrificante cultivado em meio autotrófico sob condições anóxicas. 119 , 2004.

KLEIN, Alana Carina. Cromatografia iônica como método analítico alternativo para a análise quantitativa de analitos. 2010 [citado 6 de dezembro de 2020]; Disponível em: https://bit.ly/2JV7zZm. Acesso em: 08/09/2021.

KUHN, Márcio Roberto; ZART, Nathália; OLIVEIRA, Eniz Conceição. Avaliação físico-química e microbiológica da qualidade das águas dos poços artesianos que abastecem o distrito de Boa Vista, no município de Triunfo - RS. Revista Destaques Acadêmicos [Internet]. 24 de dezembro de 2015 [citado 6 de dezembro de 2020];7(4). Disponível em: https://bit.ly/39LJTBG. Acesso em: 08/09/2021. 
MATSON, Pamela A.; NAYLOR, Rosamond; ORTIZ-MONASTERIO, Ivan. Integration of Environmental, Agronomic, and Economic Aspects of Fertilizer Management. Science (New York, NY). 280: 112-5, 3 de abril de 1998.

MELO, José Geraldo et al. Problemas de manejo de águas subterrâneas em ambientes urbanos: o caso do Município de Natal, RN. In: XIX Simpósio Brasileiro de Recursos Hídricos, 12, 2011, Maceió-Al. Anais... Maceio: Centro Cultural e de Exposições Ruth Cardoso, 2011.

MINISTÉRIO DA SAÚDE (BR), Portaria de Consolidação № $\mathbf{5}$, de 28 de setembro de 2017. Consolidação das normas sobre as ações e os serviços de saúde do Sistema Único de Saúde.

MINISTÉRIO DA SAÚDE (BR), VIGIÁGUA. Brasília, 2019. Disponível em: https://bit.ly/3kT9o6S. Acesso em: 08/09/2021.

OLIVEIRA Juliana Ribeiro Alexandre., VILELA Lourival, AYARZA Miguel Angel. Nitrate adsorption in cerrado oxisoils. Pesquisa Agropecuária Brasileira. Junho de 2000;35(6): 1199-205.

PESSOA, Mariana Lisboa (Org.). Saneamento no RS. In: Atlas FEE. Porto Alegre: FEE, 2017. Disponível em: https://bit.ly/3jRDO8m. Acesso em: 08/09/2021.

PRADO, Hélio. Pedologia fácil: aplicações em solos tropicais. 2013. Disponível em: https://bit.ly/34P9OWa. Acesso em: 08/09/2021.

PREVEDELLO Celso Luiz. Física do solo com problemas resolvidos. Curitiba: SAEAFS; 1996.

PROCEDIMENTO OPERACIONAL PADRÃO - POP/CON 060. LACEN/CEVS. Determinação de resíduos de glifosato e AMPA em água de consumo humano por cromatografia iônica. Seção Contaminantes, Rev. 03, 2019. 
RESENDE, Álvaro Vilela. Agricultura e qualidade da água: contaminação de água por nitrato. Planaltina: Embrapa Cerrados, 2002.

REZENDE, Driano et al. Aplicação de membranas de ultra e nanofiltração na remoção de nitrato em águas. In: Associação Portuguesa de Engenharia Sanitária e Ambiental (APESB); 2016 [citado 6 de dezembro de 2020]. Disponível em: https://bit.ly/2VJyjPk. Acesso em: 08/09/2021.

SANGOI, Luís. et al. Nitrogen leaching as affected by urea application method and oat residue management in soils with contrasting textures. Ciência Rural. 33(1): 6570, fevereiro de 2003.

RIO GRANDE DO SUL (BR) SECRETARIA DE PLANEJAMENTO E GESTÃO DO ESTADO. Tipos de Solo. Porto Alegre, 15 de fev. 2017. Disponível em: https://bit.ly/3en7KrJ. Acesso em: 08/09/2021.

SOUTO, Marco; Okada Marina; Okada Isaura; Dovidauskas Sérgio. A determinação de nitrato em águas por espectrofotometria UV: usos e precauções. Revista do Instituto Adolfo Lutz (Impresso). 65(1): 66-70, 2006.

SPIRO, Tomas G.; STIGLIANI, William M. Química Ambiental. 2. Ed. São Paulo: Pearson, 2008.

TORRES, Rafael Melo. Remoção biológica de nitrato em água de abastecimento humano utilizando o endocarpo de coco como fonte de carbono. 22 de agosto de 2011 [citado 6 de dezembro de 2020]. Disponível em: https://bit.ly/2JRBJwH. Acesso em: 08/09/2021.

VIOLA, Ricardo et al. Adubação verde e nitrogenada na cultura do trigo em plantio direto. Bragantia. 72(1): 90-100, 16 de abril de 2013.

Enviado: Maio, 2021.

Aprovado: Outubro, 2021. 